\title{
Variable Scan Rate Cyclic Voltammetry and Theoretical Studies on Tocopherol (Vitamin E) Model Compounds
}

\author{
Wei Wei Yao, Hong Mei Peng, and Richard D. Webster* \\ Division of Chemistry and Biological Chemistry, School of Physical and Mathematical Sciences, Nanyang \\ Technological University, Singapore 637371
}

Peter M. W. Gill

Research School of Chemistry, Australian National University, Canberra ACT 0200, Australia

Received: November 19, 2007; Revised Manuscript Received: February 4, 2008

\begin{abstract}
Variable scan rate $\left(0.1-500 \mathrm{~V} \mathrm{~s}^{-1}\right)$ cyclic voltammetry experiments were performed on a series of model tocopherol (vitamin E) compounds with differing degrees of methyl substitution around the aromatic (phenolic) ring. $\alpha$-Tocopherol, with a fully methylated aromatic ring, produced stable phenoxonium cations upon oxidation in $\mathrm{CH}_{3} \mathrm{CN}$, and was modeled via an ECE mechanism (where "E" represents an electron transfer and " $\mathrm{C}$ " a chemical step). Compounds with less methyl substitution around the aromatic ring were more reactive following oxidation, and formed additional oxidation products (hemiketals and $p$-quinones), and were modeled according to a more complicated ECECC mechanism. The equilibrium and rate constants associated with the chemical steps were estimated by digital simulations of the variable scan rate data over a range of temperatures $(T=$ $253-313 \mathrm{~K}$ ) in acetonitrile containing $0.5 \mathrm{M} \mathrm{Bu}_{4} \mathrm{NPF}_{6}$ as the supporting electrolyte. The relative lifetimes of the phenoxonium cations of tocol and the tocopherols were compared with theoretical results obtained from molecular orbital calculations.
\end{abstract}

\section{Introduction}

Vitamin E comprises a series of phenolic compounds (tocols, tocopherols, and tocotrienols) that are produced by plants, some of which are essential to human health. In this work, vitamin E refers to the collection of tocol $\left(\mathrm{H}_{3}-\mathrm{TOH}\right)$ and tocopherols $(\alpha-$, $\beta-, \gamma-$, and $\delta-\mathrm{TOH})$ that differ in their degree of methyl substitution around the phenolic ring (Scheme 1). There are currently two conflicting schools of thought regarding the biological function of vitamin E. One school takes the traditional and most widely accepted view that vitamin E's sole function is as an antioxidant, which is essentially a sacrificial compound that preferentially reacts with harmful free radicals thereby preventing lipid peroxidation (via a well-established radical termination mechanism). ${ }^{1,2}$ The second theory is that vitamin E (primarily the $\alpha$-tocopherol form) is involved in specific cellular signaling mechanisms, instead of, or in addition to, its antioxidant functions, although the mechanism at the molecular level is not currently understood. ${ }^{3}$ It is likely that the latter scenario (should it occur) also involves oxidized forms of vitamin $\mathrm{E}$; therefore, electrochemical experiments can provide useful mechanistic information regarding potential in vivo reactions.

The electrochemical behavior of the tocopherols in acetonitrile and dichloromethane solutions has been studied extensively ${ }^{4-6}$ and has recently been reviewed. ${ }^{6 f}$ The overall electrochemical mechanism can be considered to be similar to that proposed for other phenols ${ }^{7}$ with some important exceptions (Scheme 2). In the absence of added acid or base, initial one-electron oxidation of the tocopherols (TOH) produces the cation radicals $\left(\mathrm{TOH}^{\cdot+}\right)$, which lose a proton to form the phenoxyl radicals (TO'). Evidence for the initial

\footnotetext{
*E-mail:webster@ntu.edu.sg.
}

SCHEME 1: Structures of the Tocol $\left(\mathrm{H}_{3}-\mathrm{TOH}\right)$ and Tocopherol $\left(\alpha-, \beta-, \gamma-\right.$, and $\delta$-TOH) Forms of Vitamin $\mathrm{E}^{a}$

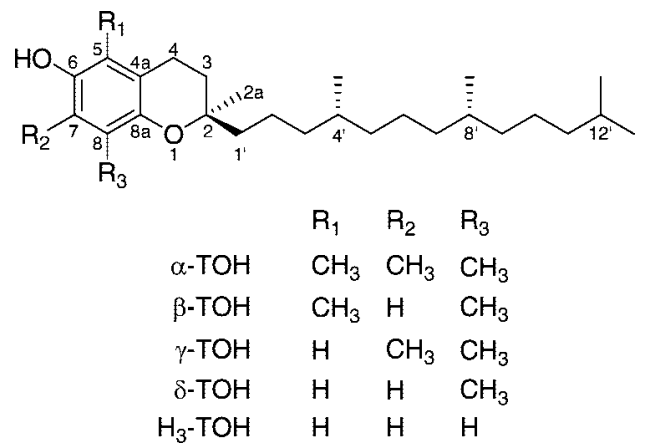

${ }^{a}$ Tocol has no known biological activity. Tocotrienol forms of vitamin $\mathrm{E}$ are similar but have an unsaturated phytyl tail in position 1'.

charge transfer and chemical step occurring consecutively (separately), rather than concertedly (simultaneously), ${ }^{8}$ came from spectroscopic measurements in dry acidic conditions that allowed detection of the cation radical. ${ }^{4,6}$ In the absence of acid, the phenoxyl radicals (having less positive oxidation potentials than the starting phenols) undergo immediate further one-electron oxidation to form the phenoxonium cations $\left(\mathrm{TO}^{+}\right)$in an ECE ("E" represents electron transfer and "C" represents a chemical step) mechanism. ${ }^{4,6}$ The principal differences observed in the electrochemical behavior of the tocopherols, when compared to most other phenols, are that (i) the oxidation reaction is chemically reversible on the cyclic voltammetry (CV) time scale (and for the $\alpha$ and $\beta$ forms is reversible on electrolysis time scales ${ }^{6 \mathrm{~d}}$ ), and (ii) the cation radicals and phenoxonium cations are stable enough to be detected by cyclic voltammetry and in some cases by spectroscopy. The phenoxonium cation of $\alpha$-toco- 
SCHEME 2: Electrochemically Induced Transformations of Vitamin $\mathrm{E}$ and Model Compounds in Dry $\mathrm{CH}_{3} \mathrm{CN}$ or $\mathrm{CH}_{2} \mathrm{Cl}_{2}{ }^{6 a}$

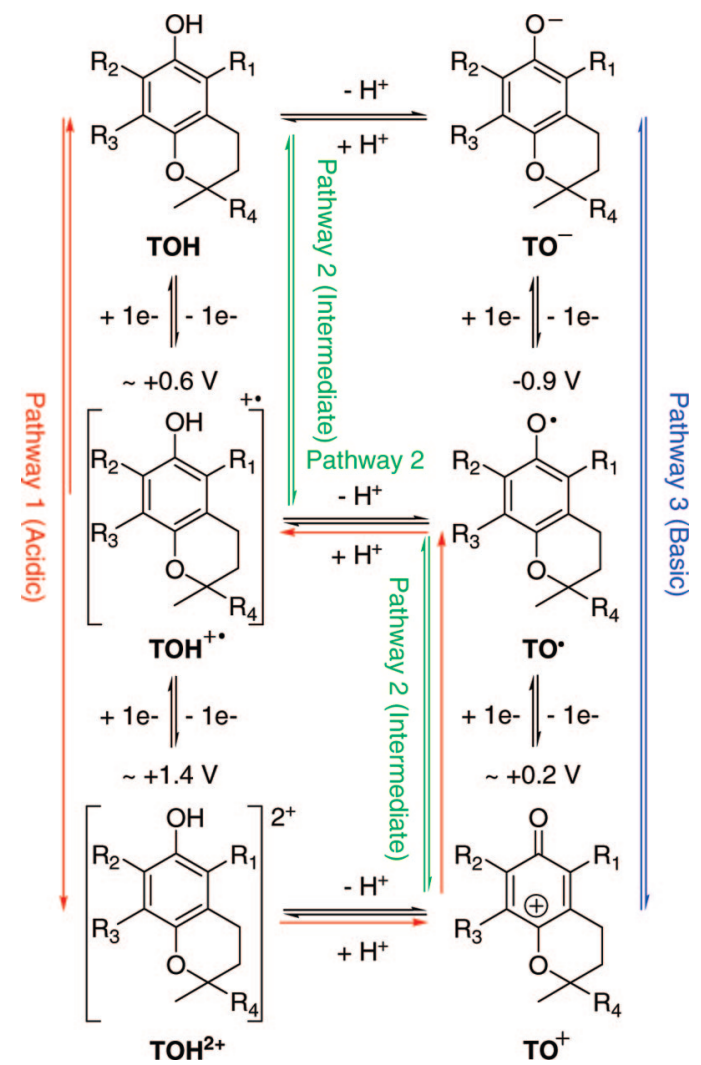

${ }^{a}$ One resonance structure is displayed for each compound. The listed potentials (vs ferrocene $\mathrm{e}^{0 /+}$ ) were obtained by voltammetry; they are the approximate values necessary to bring about oxidation of the phenolic compounds but do not necessarily correspond to the formal potential. The counterions for the charged species are the supporting electrolyte cation $\left[\mathrm{Bu}_{4} \mathrm{~N}^{+}\right]$and anion $\left[\mathrm{PF}_{6}{ }^{-}\right]$, and the " $\mathrm{H}^{+}$" ions exist coordinated to the organic solvent. $\mathrm{R}_{1}, \mathrm{R}_{2}, \mathrm{R}_{3}=\mathrm{H}$ or $\mathrm{CH}_{3} . \mathrm{R}_{4}=\mathrm{CH}_{3}$ or $\left(\mathrm{CH}_{2} \mathrm{CH}_{2} \mathrm{CH}_{2} \mathrm{CH}\left(\mathrm{CH}_{3}\right)\right)_{3} \mathrm{CH}_{3}$.

pherol $\left(\alpha-\mathrm{TO}^{+}\right)$is particularly stable and can even be isolated as a pure solid compound when crystallized with a nonnucleophilic counteranion. ${ }^{6 e}$

The mechanism in Scheme 2 has largely been determined by slow scan rate $\mathrm{CV}$ and controlled potential electrolysis experiments, ${ }^{4,6}$ combined with detailed spectroscopic analysis (EPR, FTIR, NMR, and UV-vis spectroscopies and X-ray crystallography), ${ }^{6}$ although there currently exist few kinetic data for the homogeneous chemical steps. This study uses variable scan rate cyclic voltammetry between 0.1 and $500 \mathrm{~V} \mathrm{~s}^{-1}$ to study kinetic aspects of the reactions that occur in Scheme 2, as well as the additional steps associated with secondary oxidation processes that occur for the less methylated tocol and tocopherols $\left(\mathrm{H}_{3^{-}}, \gamma-, \delta\right.$-TOH). In all cases the model compounds were used where the phytyl tails were replaced with methyl groups (position 1' in Scheme 1), since these compounds can be synthesized in a higher degree of purity (than the oil-like natural compounds) and their electrochemical behavior has been shown to be identical to the natural compounds (Scheme 3). ${ }^{6 c, g}$ The electrochemical experiments were complemented with results from high-level theoretical calculations on the phenoxonium cations, in order to determine whether there is a relationship between the observed lifetimes in solution, and the structure and positive charge distribution within the phenoxonium cations.
SCHEME 3: Structures of the Model Tocopherol and Tocol Compounds Used in This Study, Where the Phytyl Tail Is Replaced with a Methyl Group<smiles>Cc1c(C)c2c(c(C)c1O)CCC(C)(C(C)C)O2</smiles>

\section{Experimental Section}

2.1. Chemicals. Tocol, ${ }^{9}$ the model tocopherols, ${ }^{10}$ and $\mathrm{Bu}_{4} \mathrm{NPF}_{6}{ }^{11}$ were prepared by standard methods. HPLC-grade $\mathrm{CH}_{3} \mathrm{CN}, \mathrm{CH}_{2} \mathrm{Cl}_{2}$, dimethylformamide (DMF), and dimethyl sulfoxide (DMSO) were used as received.

2.2. Electrochemical Procedures. Cyclic voltammetric (CV) experiments were conducted with a computer-controlled Eco Chemie Autolab PGSTAT 100 with an ADC fast scan generator. Working electrodes were $1 \mathrm{~mm}, 0.1 \mathrm{~mm}, 50 \mu \mathrm{m}$, and $20 \mu \mathrm{m}$ diameter planar Pt disks, used in conjunction with a Pt auxiliary electrode and an $\mathrm{Ag}$ wire reference electrode connected to the test solution via a salt bridge containing $0.5 \mathrm{M} \mathrm{Bu}_{4} \mathrm{NPF}_{6}$ in $\mathrm{CH}_{3} \mathrm{CN}$. Accurate potentials were obtained using ferrocene as an internal standard. Variable-temperature (253-313 K) experiments were controlled with a Thermo Electron Neslab RTE 740 circulating bath.

2.3. Theoretical Calculations. Digital simulations of the CV data were performed using the DigiElch software package. ${ }^{12}$ Molecular orbital calculations were performed using a development version of the Q-Chem 3.1 software package ${ }^{13}$ and the Spartan '04 software package. ${ }^{14}$ Electrostatic potential maps and potential-derived atomic charges were computed by Spartan at the B3LYP/6-31G* level using structures optimized at the same level.

\section{Results and Discussion}

3.1. $\left(\mathbf{C H}_{3}\right) \alpha-\mathrm{TOH}$. Cyclic voltammograms $(\mathrm{CVs})$ of $\left(\mathrm{CH}_{3}\right) \alpha-$ $\mathrm{TOH}$ in $\mathrm{CH}_{3} \mathrm{CN}$ over a range of scan rates are shown in Figure

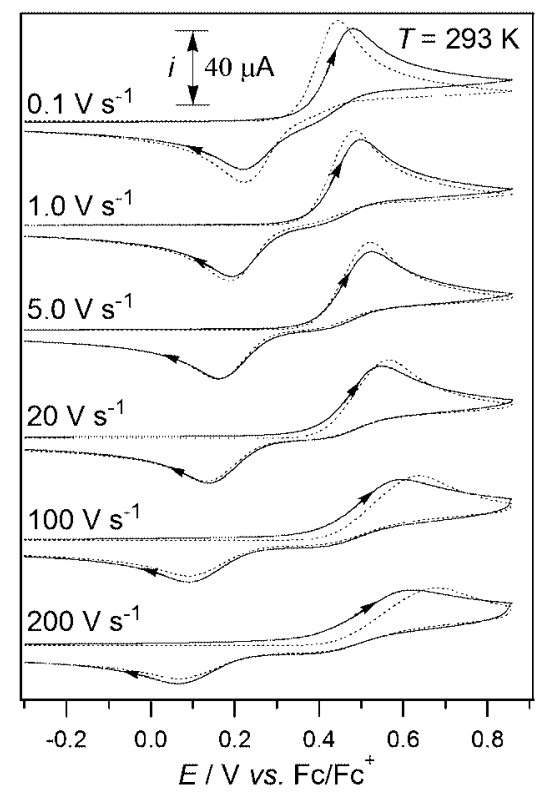

Figure 1. $\mathrm{CVs}$ of $2 \mathrm{mM}\left(\mathrm{CH}_{3}\right) \alpha-\mathrm{TOH}$ in $\mathrm{CH}_{3} \mathrm{CN}$ with $0.5 \mathrm{M} \mathrm{Bu}_{4} \mathrm{NPF}_{6}$ at different scan rates $(v)$ at a $1 \mathrm{~mm}$ diameter Pt electrode. Current data were scaled by multiplying by $v^{-0.5}$. (-) Experimental data. (---) Digital simulations (see parameters in Table 1). 
TABLE 1: Equilibrium, Rate Constants, and Electrochemical Parameters Obtained by Digital Simulation of CV ${ }^{a}$ Data for the ECE Reaction Given in Scheme 5 (Pathway 2 in Scheme 2)

\begin{tabular}{ccccccc}
\hline compound & solvent & $E_{\mathrm{f}(1)}^{0} / \mathrm{V}$ & $E_{\mathrm{f}(2)}^{0} / \mathrm{V}$ & $K_{\mathrm{eq}(1)}^{c} / \mathrm{mol} \mathrm{L}^{-1}$ & $k_{\mathrm{f}(1)}^{c} / \mathrm{s}^{-1}$ \\
\hline$\left(\mathrm{CH}_{3}\right) \alpha-\mathrm{TOH}$ & $\mathrm{CH}_{3} \mathrm{CN}$ & $+0.50 \pm 0.05$ & $+0.15 \pm 0.05$ & $1.2( \pm 1.0) \times 10^{-4}$ & $3.0( \pm 2) \times 10^{4}$ & $2.5( \pm 2) \times 10^{8}$ \\
$\left(\mathrm{CH}_{3}\right) \alpha-\mathrm{TOH}$ & $\mathrm{CH}_{2} \mathrm{Cl}$ & $+0.50 \pm 0.05$ & $+0.15 \pm 0.05$ & $1.2( \pm 1.0) \times 10^{-5}$ & $3.0( \pm 2) \times 10^{5}$ & $2.5( \pm 2) \times 10^{10}$ \\
$\left(\mathrm{CH}_{3}\right) \gamma-\mathrm{TOH}$ & $\mathrm{CH}_{3} \mathrm{CN}$ & $+0.55 \pm 0.05$ & $+0.25 \pm 0.05$ & $2.0( \pm 1.5) \times 10^{-4}$ & $3.0( \pm 2) \times 10^{3}$ & $1.5( \pm 1) \times 10^{7}$ \\
$\left(\mathrm{CH}_{3}\right) \delta$-TOH & $\mathrm{CH}_{3} \mathrm{CN}$ & $+0.65 \pm 0.05$ & $+0.30 \pm 0.05$ & $2.0( \pm 1.5) \times 10^{-4}$ & $5.0( \pm 4) \times 10^{4}$ & $2.5( \pm 2) \times 10^{8}$ \\
$\left(\mathrm{CH}_{3}\right) \mathrm{H}_{3}-\mathrm{TOH}$ & $\mathrm{CH}_{3} \mathrm{CN}$ & $+0.75 \pm 0.05$ & $+0.40 \pm 0.05$ & $1.7( \pm 1.5)$ & $2.5( \pm 2) \times 10^{5}$ & $1.5( \pm 1) \times 10^{6}$
\end{tabular}

${ }^{a} \mathrm{CV}$ data recorded with $0.5 \mathrm{M} \mathrm{n}$ - $\mathrm{Bu}_{4} \mathrm{NPF}_{6}$ as the supporting electrolyte with $20 \mu \mathrm{m}, 50 \mu \mathrm{m}, 0.1 \mathrm{~mm}$, and $1 \mathrm{~mm}$ diameter Pt electrodes, at scan rates between 0.1 and $500 \mathrm{~V} \mathrm{~s}^{-1}$ and at temperatures from 313 to $253 \mathrm{~K}^{b}{ }^{b}$ Formal potential vs $\mathrm{Fc}_{\mathrm{Fc}}{ }^{+}$. Heterogeneous rate constants were estimated to be between 0.1 and $0.3 \mathrm{~cm} \mathrm{~s}^{-1}$. Diffusion coefficient values $\left(2.5 \times 10^{-5} \mathrm{~cm}^{2} \mathrm{~s}^{-1}\right.$ at $313 \mathrm{~K}$ to $0.3 \times 10^{-5} \mathrm{~cm}^{2} \mathrm{~s}^{-1}$ at $\left.253 \mathrm{~K}\right)$ for the starting materials were estimated by simulation techniques (the same values were used for all oxidized forms of the same compound). ${ }^{c}$ Homogeneous equilibrium and rate constants. The range in these values reflects the error associated with the simulations due to the high number of variables and because the forward $\left(k_{\mathrm{f}(1)}\right)$ and reverse $\left(k_{\mathrm{b}(1)}\right)$ steps are very fast (see text).

SCHEME 4: Homogeneous Electron Transfer Reaction (Disproportionation Step)

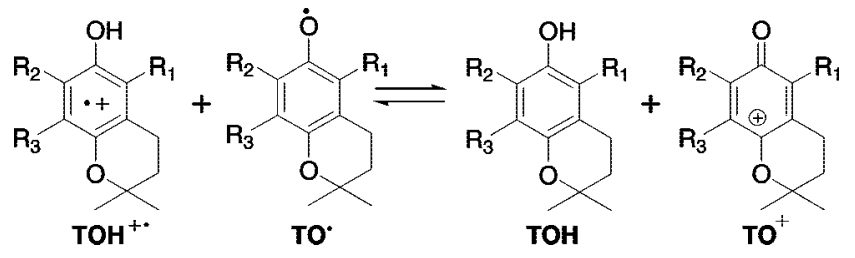

1 (solid lines), along with the corresponding digital simulations (dashed lines). The CVs were modeled based on the pathway 2 mechanism in Scheme 2, where the forward positive potential scan involved the chemically reversible transformation of the phenol into the phenoxonium cation $\left[\left(\mathrm{CH}_{3}\right) \alpha-\mathrm{TO}^{+}\right]$via two oneelectron-oxidation steps and an accompanying proton loss (an ECE mechanism). When the scan direction was reversed, a reductive peak was detected that was associated with the transformation of the phenoxonium cation back to the starting material. The data in Figure 1 illustrate that the ratio of the oxidative $\left(i_{\mathrm{p}}{ }^{\mathrm{ox}}\right)$ to reductive $\left(i_{\mathrm{p}}{ }^{\text {red }}\right)$ peak currents $\left(i_{\mathrm{p}}{ }^{\mathrm{ox}} / i_{\mathrm{p}}{ }_{\mathrm{p}}^{\text {red }}\right)$ remained approximately constant as the scan rate was increased, while the anodic $\left(E_{\mathrm{p}}{ }^{\text {ox }}\right)$ to cathodic $\left(E_{\mathrm{p}}{ }^{\text {red }}\right)$ peak-to-peak separation $\left(\Delta E_{\mathrm{pp}}\right)$ increased with increasing scan rate.

Because the reduction potential of the cation radical $\left(\mathrm{TOH}^{\circ+}\right)$ is greater than the oxidation potential of the phenoxyl radical (TO*) by approximately $+0.4 \mathrm{~V}$, the two compounds should undergo a homogeneous charge transfer reaction to form the phenoxonium cation $\left(\mathrm{TO}^{+}\right)$and regenerate the starting material (TOH) (Scheme 4). It is very difficult to experimentally determine whether the reaction in Scheme 4 (termed a disproportionation step ${ }^{15}$ ) occurs instead of the second heterogeneous charge transfer step, or whether the ECE mechanism, as illustrated by pathway 2 in Scheme 2, solely takes place. It is possible that the mechanisms in both Schemes 2 and 4 occur simultaneously, depending on whether the TO* radical encounters the electrode surface (heterogeneous charge transfer) or encounters a cation radical (homogeneous charge transfer) and depending on the relative rates of the heterogeneous and homogeneous charge transfer steps. The electrochemical data were modeled only on the ECE mechanism. One observation that favors the simpler ECE mechanism is that the reaction is completely chemically reversible. In order for the disproportionation mechanism to occur, the equilibrium and rate constants for the $\mathrm{C}$ step and disproportionation step would both coincidentally need be "tuned" to allow the reactions to favorably progress in either direction.

It was possible to obtain a simulated voltammogram that very closely matched the experimental voltammogram for any individual scan rate, when modeled according to the pathway
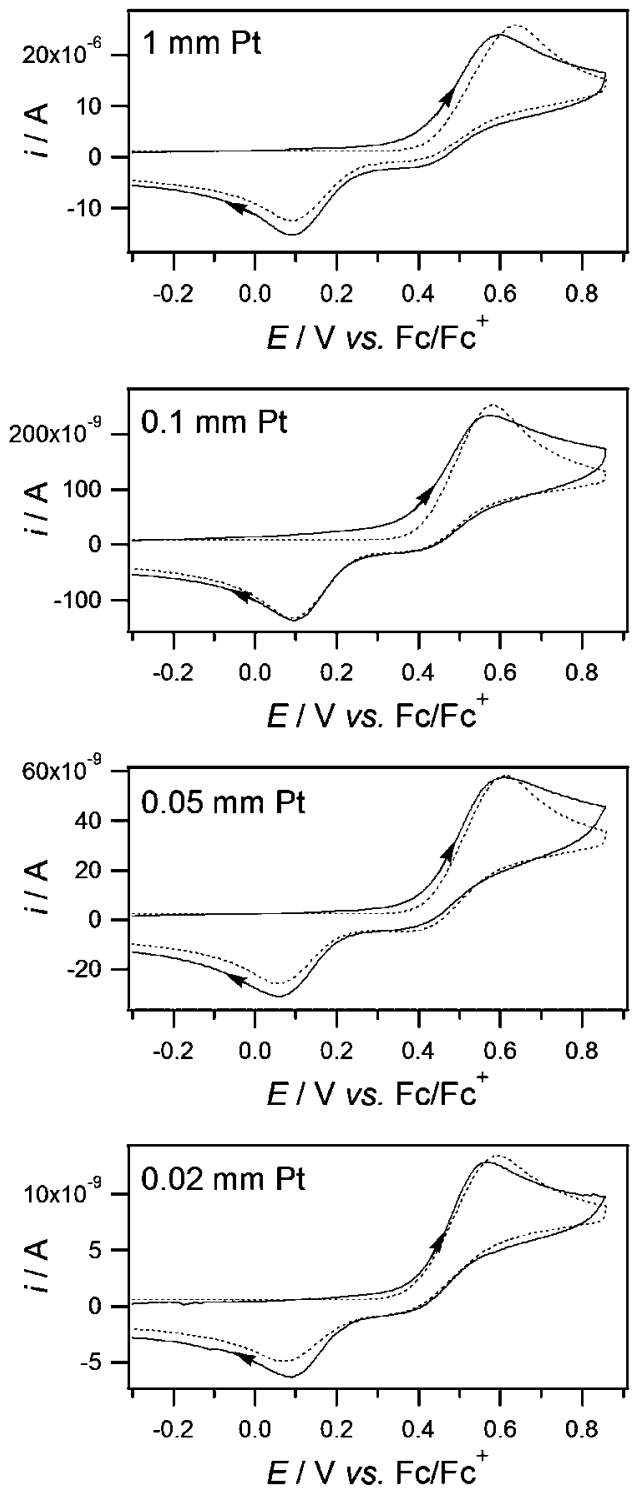

Figure 2. $\mathrm{CVs}$ of $2 \mathrm{mM}\left(\mathrm{CH}_{3}\right) \alpha-\mathrm{TOH}$ in $\mathrm{CH}_{3} \mathrm{CN}$ with $0.5 \mathrm{M} \mathrm{Bu}_{4} \mathrm{NPF}_{6}$ at $293 \mathrm{~K}$ at different size Pt working electrodes. The scan rate $=100$ $\mathrm{V} \mathrm{s}^{-1}$. (-) Experimental data. (---) Digital simulations (see parameters in Table 1).

2 mechanism in Scheme 2. However, no series of simulated voltammograms exactly matched the experimental data when a range of scan rates were used with the same simulation parameters. Therefore, the simulation results presented in Figure 1 (and other figures) represent the best average values, taking into account that data were collected over a large range of scan rates and at different size electrodes. 

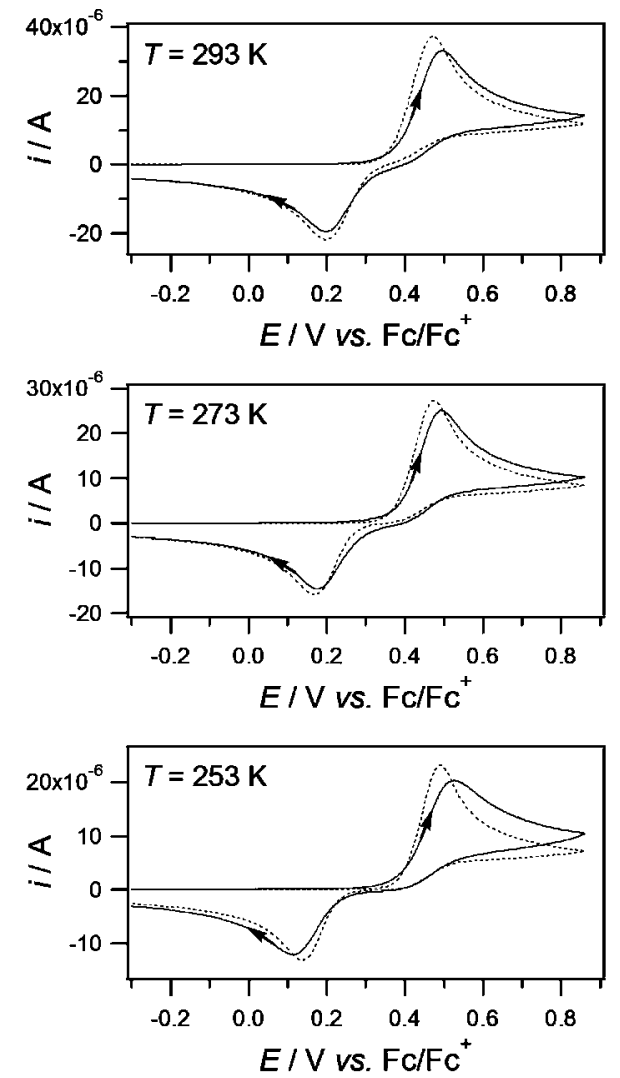

Figure 3. $\mathrm{CVs}$ of $2 \mathrm{mM}\left(\mathrm{CH}_{3}\right) \alpha-\mathrm{TOH}$ in $\mathrm{CH}_{3} \mathrm{CN}$ with $0.5 \mathrm{M} \mathrm{Bu}_{4} \mathrm{NPF}_{6}$ at a scan rate of $0.5 \mathrm{~V} \mathrm{~s}^{-1}$ at variable temperatures at a $1 \mathrm{~mm}$ diameter Pt electrode. (-) Experimental data. (---) Digital simulations (see parameters in Table 1).

Figure 2 shows the CVs obtained at electrodes of several sizes, demonstrating that, at a scan rate of $100 \mathrm{~V} \mathrm{~s}^{-1}$, the $\Delta E_{\mathrm{pp}}$ values remain approximately constant at the different electrodes. Considering that the effects of uncompensated solution resistance are the highest at the largest surface area electrode, the close similarity in the peak separations in the voltammograms in Figure 2 indicates that the increasing $\Delta E_{\mathrm{pp}}$ values shown in Figure 1 at faster scan rates are mainly the result of relatively slow heterogeneous electron transfer rates $\left(k_{\mathrm{s}}\right)$, rather than the effects of uncompensated solution resistance. By comparing the $\Delta E_{\mathrm{pp}}$ values obtained for ferrocene under identical conditions (where it was assumed that the $k_{\mathrm{s}}$ value was $\geq 1 \mathrm{~cm} \mathrm{~s}^{-1}$ ), ${ }^{16}$ estimates on the solution resistance at varying temperatures were made and incorporated into the simulations.

Figure 3 shows $\mathrm{CVs}$ obtained of $\left(\mathrm{CH}_{3}\right) \alpha-\mathrm{TOH}$ at various temperatures, illustrating that the $i_{\mathrm{p}}{ }^{\mathrm{ox}} / i_{\mathrm{p}}$ red ratios and $\Delta E_{\mathrm{pp}}$ values remain close to constant as the temperature is changed. It was found that varying the scan rate between 0.1 and $500 \mathrm{~V} \mathrm{~s}^{-1}$ while varying the temperature between 253 and $313 \mathrm{~K}$ did not significantly alter the position $(\mathrm{V})$ or ratio $\left(i_{\mathrm{p}}{ }^{\mathrm{ox}} / i_{\mathrm{p}}{ }^{\text {red }}\right)$ of the voltammetric waves beyond differences that could be assigned due to solution resistance or slow rates of heterogeneous electron transfer. Therefore, it can be concluded that the homogeneous proton transfer reaction in Scheme 2, which occurs between $\left(\mathrm{CH}_{3}\right) \alpha-\mathrm{TOH}^{\circ+}$ and $\left(\mathrm{CH}_{3}\right) \alpha-\mathrm{TO}^{\circ}$, occurs sufficiently quickly at all temperatures so as not to be outrun at scan rates $\leq 500 \mathrm{~V}$ $\mathrm{s}^{-1}$ in $\mathrm{CH}_{3} \mathrm{CN}$ solutions. Due to the number of steps involved in the oxidation process and because the homogeneous step occurred relatively quickly, it was possible to obtain simulations that matched the experimental data for a number of values of the forward $\left(k_{\mathrm{f}(1)}\right)$ and reverse $\left(k_{\mathrm{b}(1)}\right)$ rate constants (Scheme 5), with the range of values given in Table 1 . The simulations indicate that the forward and reverse reactions are both fast, with the protonation rate approaching that of a diffusioncontrolled process.

The voltammetric results obtained in $\mathrm{CH}_{2} \mathrm{Cl}_{2}$ solutions over a variety of temperatures and scan rates were similar to the data obtained in $\mathrm{CH}_{3} \mathrm{CN}$, although affected by the higher solution resistance associated with the low dielectric constant solvent. At slow scan rates $\leq 0.2 \mathrm{~V} \mathrm{~s}^{-1}$, the CVs showed an additional reductive peak when the scan direction was reversed (Figure 4), but at faster scan rates the voltammograms were very similar in appearance to those obtained in $\mathrm{CH}_{3} \mathrm{CN}$ solutions.

The voltammograms obtained for $\left(\mathrm{CH}_{3}\right) \alpha-\mathrm{TOH}$ in dimethylformamide (DMF) and dimethyl sulfoxide (DMSO) solutions were significantly different from those obtained in $\mathrm{CH}_{3} \mathrm{CN}$ or $\mathrm{CH}_{2} \mathrm{Cl}_{2}$ (Figure 4). CVs obtained of $\left(\mathrm{CH}_{3}\right) \alpha-\mathrm{TOH}$ in DMF and DMSO solutions at scan rates up to $500 \mathrm{~V} \mathrm{~s}^{-1}$ showed only a forward oxidative process with no evidence of a cathodic peak associated with reduction of the phenoxonium cation back to the phenol (as occurs in $\mathrm{CH}_{3} \mathrm{CN}$ and $\mathrm{CH}_{2} \mathrm{Cl}_{2}$ ). Therefore, the $\mathrm{CV}$ results provide no evidence for the existence of the persistent phenoxonium cations in DMF and DMSO, which is an unexpected result since the electrochemical behaviors of compounds in the aprotic solvents $\mathrm{CH}_{3} \mathrm{CN}$ and DMF are usually alike. ${ }^{17} \mathrm{~A}$ further observation was that the peak potentials for the oxidation process in DMF and DMSO were shifted to less positive potentials compared to in $\mathrm{CH}_{3} \mathrm{CN}$ and $\mathrm{CH}_{2} \mathrm{Cl}_{2}$.

The $i_{\mathrm{p}}{ }^{\text {ox }}$ values for the oxidation process were much lower in DMF and DMSO compared to those recorded in $\mathrm{CH}_{3} \mathrm{CN}$ and $\mathrm{CH}_{2} \mathrm{Cl}_{2}$ (Figure 4). The lower peak currents can partly be explained by decreasing diffusion coefficient values in the more viscous solvents DMF and DMSO. Coulometry data collected during exhaustive controlled-potential oxidative electrolysis experiments on $\left(\mathrm{CH}_{3}\right) \alpha-\mathrm{TOH}$ allowed the calculation of 2.2 electrons/molecule in DMF and over 4 electrons/molecule in DMSO solutions, indicating a complicated long-term oxidation mechanism. The small voltammetric peak detected at $-1.0 \mathrm{~V}$ vs $\mathrm{Fc} / \mathrm{Fc}^{+}$when the scan direction was reversed for $\left(\mathrm{CH}_{3}\right) \alpha$ $\mathrm{TOH}$ in DMSO or DMF (Figure 4) became larger during the electrolysis experiments, indicating that it was due to a secondary oxidation product (but not the phenoxonium cation). By comparison with an authentic sample, it was determined that the species responsible for the peak at $-1.0 \mathrm{~V}$ was not the $\alpha$-tocopherol quinone, which is known to be a long-term oxidation product. ${ }^{18}$ Therefore, it appears that the oxidation process in DMF and DMSO occurs through a more complicated mechanism than that shown in Scheme 2.

3.2. $\left(\mathrm{CH}_{3}\right) \boldsymbol{\gamma}$-TOH, $\left(\mathrm{CH}_{3}\right) \delta$-TOH, and $\left(\mathrm{CH}_{3}\right) \mathrm{H}_{3}-\mathrm{TOH}$. The cyclic voltammograms obtained for the tocopherols and tocol in $\mathrm{CH}_{3} \mathrm{CN}$, with fewer methyl groups in the aromatic ring, were more complex than those for the fully methylated form. Figure 5 shows cyclic voltammograms obtained for $\left(\mathrm{CH}_{3}\right) \gamma$-TOH over a range of scan rates. (Experimental data for $\left(\mathrm{CH}_{3}\right) \delta$-TOH and $\left(\mathrm{CH}_{3}\right) \mathrm{H}_{3}-\mathrm{TOH}$ showed similar features.) At a scan rate of 0.1 $\mathrm{V} \mathrm{s}^{-1}$, a reductive peak was detected when the scan direction was reversed at $-0.3 \mathrm{~V}$ vs $\mathrm{Fc} / \mathrm{Fc}^{+}$. When the scan rate was increased to $10 \mathrm{~V} \mathrm{~s}^{-1}$, the reductive peak at $-0.3 \mathrm{~V}$ vs $\mathrm{Fc} / \mathrm{Fc}^{+}$ disappeared while concomitantly a reductive peak at $+0.2 \mathrm{~V}$ vs $\mathrm{Fc} / \mathrm{Fc}^{+}$increased in magnitude. The reductive peak at +0.2 $\mathrm{V}$ vs $\mathrm{Fc} / \mathrm{Fc}^{+}$is associated with reduction of the phenoxonium cation back to the starting material. Thus, at a scan rate of 10 $\mathrm{V} \mathrm{s}^{-1}$, the cyclic voltammogram of $\left(\mathrm{CH}_{3}\right) \gamma-\mathrm{TOH}$ appeared very similar to the $\mathrm{CV}$ of $\left(\mathrm{CH}_{3}\right) \alpha-\mathrm{TOH}$ at a scan rate of $0.1 \mathrm{~V} \mathrm{~s}^{-1}$ (compare Figures 1 and 5). The voltammetric behavior of $\left(\mathrm{CH}_{3}\right) \gamma$-TOH can be rationalized by its phenoxonium cation 
SCHEME 5: Electrochemical Oxidation Mechanism of Tocol and Tocopherols Studied by Cyclic Voltammetry over a Range of Temperatures and Scan Rates ${ }^{a}$<smiles>[R]c1c([R6])c2c(c([R])c1O)CCC(C)(C)O2</smiles>

TOH

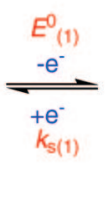

s(1)<smiles>[R5]c1c(O)c([R5])c2c(c1Br)CCC(C)(C)O2</smiles>

$\mathrm{TOH}^{+*}$

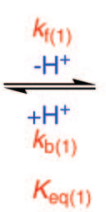

$K_{\text {eq(1) }}$

$\mathrm{R}_{3}$<smiles>CC1(C)OCCO1</smiles>

TO*

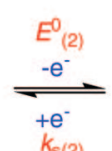

$k_{s(2)}$

(a)<smiles>[R6]C1=C([R5])[C@H]2OC(C)(C)CCC2=C([R])C1=O</smiles>

$\mathrm{TO}^{+}$

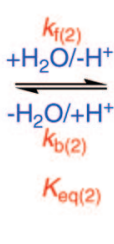<smiles>[R]C1=C([R3])C2(O)OC(C)(C)CCC2=C([R])C1=O</smiles>

TOQ(OH)

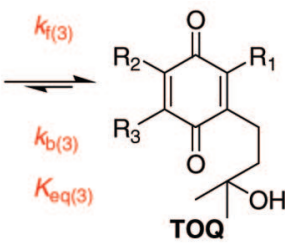

TOQ

$$
\underset{\substack{+\mathrm{TO}_{\text {bimolec }}^{\circ} \\ \text { Products }}}{E_{(3)}^{0}-\mathrm{e}^{-} \|+\mathrm{e}^{-} k_{\mathrm{s}(3)}}
$$

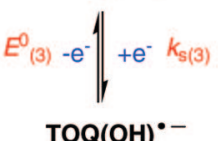

${ }^{a}$ Electrochemical, equilibrium, and kinetic values associated with the heterogeneous and homogeneous steps are given in Tables 1 and $2 . \mathrm{R}_{1}$, $\mathrm{R}_{2}$, $\mathrm{R}_{3}=\mathrm{H}$ or $\mathrm{CH}_{3}$.

TABLE 2: Equilibrium, Rate Constants and Electrochemical Parameters Obtained by Digital Simulation of $\mathrm{CV}^{b}$ Data for the

\begin{tabular}{|c|c|c|c|c|c|c|c|c|}
\hline compound & $T / \mathrm{K}$ & $E_{\mathrm{f}(3)}^{0} / \mathrm{V}$ & $K_{\mathrm{eq}(2)}^{d} / \mathrm{L} \mathrm{mol}^{-1}$ & $k_{\mathrm{f}(2)}{ }^{d} / \mathrm{L} \mathrm{mol}^{-1} \mathrm{~s}^{-1}$ & $k_{\mathrm{b}(2)}{ }^{d} / \mathrm{s}^{-1}$ & $\left.K_{\mathrm{eq}(3)}\right)^{d}$ & $k_{\mathrm{f}(3)}{ }^{d} / \mathrm{s}^{-1}$ & $k_{\mathrm{b}(3)}{ }^{d} / \mathrm{s}^{-1}$ \\
\hline \multirow[t]{3}{*}{$\left(\mathrm{CH}_{3}\right) \gamma-\mathrm{TOH}$} & 313 & -0.23 & $1 \times 10^{3}$ & $3 \times 10^{1}$ & $3 \times 10^{-2}$ & $5 \times 10^{2}$ & 0.5 & $1 \times 10^{-3}$ \\
\hline & 293 & -0.25 & $1 \times 10^{3}$ & $3 \times 10^{1}$ & $3 \times 10^{-2}$ & $5 \times 10^{2}$ & 0.1 & $2 \times 10^{-4}$ \\
\hline & 273 & -0.25 & $1 \times 10^{3}$ & 8 & $8 \times 10^{-3}$ & $5 \times 10^{2}$ & 0.1 & $2 \times 10^{-4}$ \\
\hline \multirow[t]{3}{*}{$\left(\mathrm{CH}_{3}\right) \delta-\mathrm{TOH}$} & 313 & -0.20 & $2 \times 10^{2}$ & $7 \times 10^{1}$ & $4 \times 10^{-1}$ & $5 \times 10^{2}$ & 0.5 & $1 \times 10^{-3}$ \\
\hline & 293 & -0.20 & $2 \times 10^{2}$ & $5 \times 10^{1}$ & $3 \times 10^{-1}$ & $5 \times 10^{2}$ & 0.1 & $2 \times 10^{-4}$ \\
\hline & 273 & -0.25 & $2 \times 10^{2}$ & $4 \times 10^{1}$ & $2 \times 10^{-1}$ & $5 \times 10^{2}$ & 0.1 & $2 \times 10^{-4}$ \\
\hline$\left(\mathrm{CH}_{3}\right) \mathrm{H}_{3}-\mathrm{TOH}$ & 293 & -0.12 & $1 \times 10^{3}$ & $1 \times 10^{2}$ & $1 \times 10^{-1}$ & $5 \times 10^{2}$ & 0.1 & $2 \times 10^{-4}$ \\
\hline
\end{tabular}
Follow-Up Reactions Given in Scheme $5^{a}$

${ }^{a}$ Data are not available for $\left(\mathrm{CH}_{3}\right) \alpha-\mathrm{TOH}$ because the processes occur slower than the cyclic voltammetric time scale. ${ }^{b} \mathrm{CV}$ data recorded in $\mathrm{CH}_{3} \mathrm{CN}$ (with $0.5 \mathrm{M} \mathrm{n}-\mathrm{Bu}_{4} \mathrm{NPF}_{6}$ ), at $20 \mu \mathrm{m}, 50 \mu \mathrm{m}, 0.1 \mathrm{~mm}$, and $1 \mathrm{~mm}$ diameter Pt electrodes, at scan rates between 0.1 and $500 \mathrm{~V} \mathrm{~s}{ }^{-1}$ and at temperatures from 313 to $263 \mathrm{~K} .{ }^{c}$ Formal potential vs $\mathrm{Fc} / \mathrm{Fc}^{+}$reported to the nearest $10 \mathrm{mV}$. Heterogeneous rate constants were estimated to be between 0.1 and $0.3 \mathrm{~cm} \mathrm{~s}^{-1}$. Diffusion coefficient values $\left(2.5 \times 10^{-5} \mathrm{~cm}^{2} \mathrm{~s}^{-1}\right.$ at $313 \mathrm{~K}$ to $0.5 \times 10^{-5} \mathrm{~cm}^{2} \mathrm{~s}^{-1}$ at $\left.263 \mathrm{~K}\right)$ for the starting materials were estimated by simulation techniques (the same values were used for all oxidized forms of the same compound). ${ }^{d}$ Homogeneous equilibrium and rate constants reported to one significant figure.

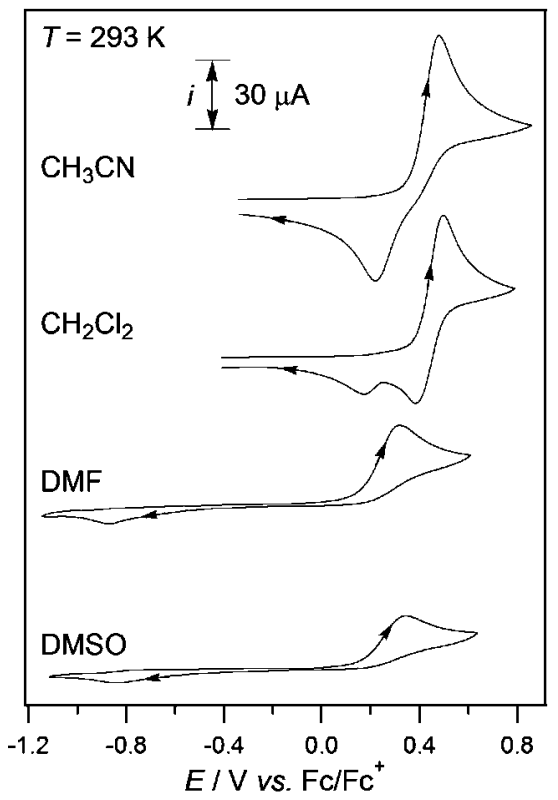

Figure 4. $\mathrm{CVs}$ of $2 \mathrm{mM}\left(\mathrm{CH}_{3}\right) \alpha-\mathrm{TOH}$ in different solvents with 0.5 $\mathrm{M} \mathrm{Bu}_{4} \mathrm{NPF}_{6}$ at a scan rate of $0.1 \mathrm{~V} \mathrm{~s}^{-1}$ at a $1 \mathrm{~mm}$ diameter Pt electrode.

formed by electrochemical oxidation being relatively short-lived, so at slower scan rates, the $i_{\mathrm{p}}{ }^{\mathrm{ox}} / i_{\mathrm{p}}$ red ratio for the phenol/ phenoxonium cation transformation was $\gg 1$.

The additional reductive peak at $-0.3 \mathrm{~V}$ vs $\mathrm{Fc} / \mathrm{Fc}^{+}$observed at slow scan rates during the oxidation of $\left(\mathrm{CH}_{3}\right) \gamma-\mathrm{TOH}$ is due

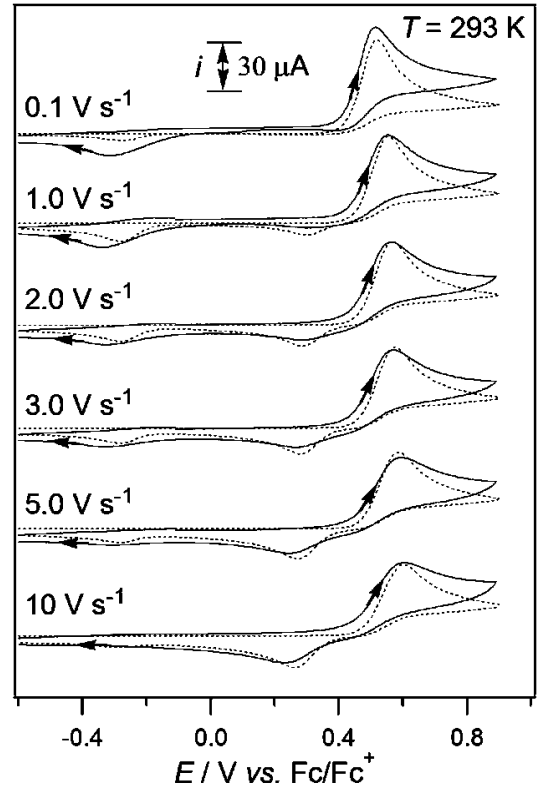

Figure 5. $\mathrm{CVs}$ of $2 \mathrm{mM}\left(\mathrm{CH}_{3}\right) \gamma-\mathrm{TOH}$ in $\mathrm{CH}_{3} \mathrm{CN}$ with $0.5 \mathrm{M} \mathrm{Bu}_{4} \mathrm{NPF}_{6}$ at different $\operatorname{scan}$ rates $(v)$ at a $1 \mathrm{~mm}$ diameter Pt electrode. Current data were scaled by multiplying by $v^{-0.5}$. (-) Experimental data. (---) Digital simulations (see parameters in Tables 1 and 2).

to a reaction product of the phenoxonium cation, and has been assigned as a hemiketal $[\mathrm{TOQ}(\mathrm{OH})]$, which subsequently converts into the $p$-quinone (TOQ) (Scheme 5)., ${ }^{4,6,18}$ Water is usually present in millimolar concentrations even in "dry" 

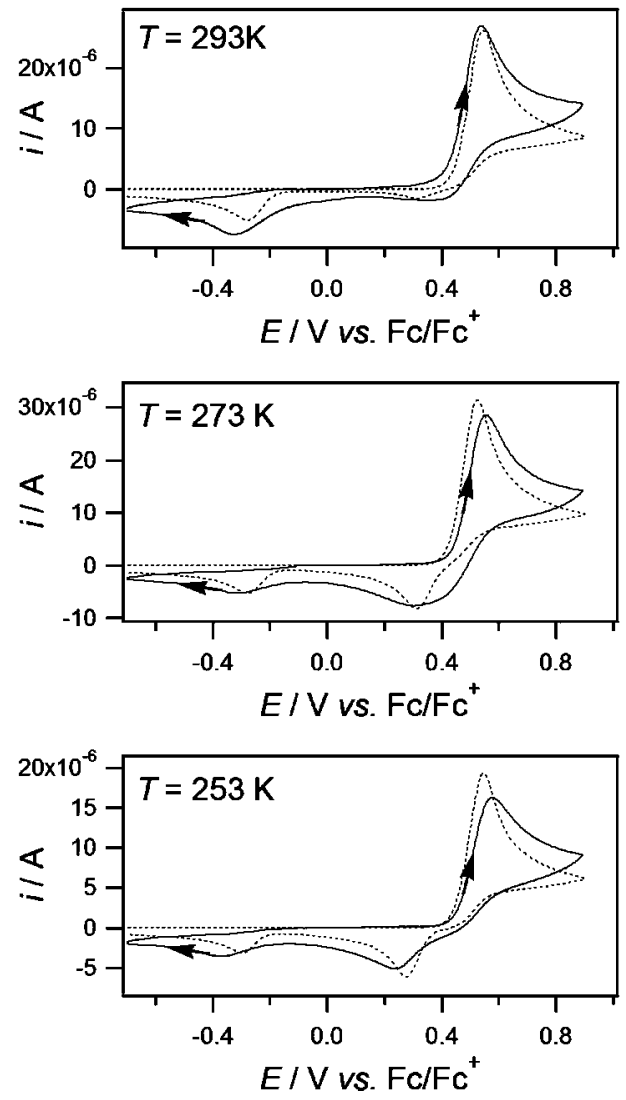

Figure 6. $\mathrm{CVs}$ of $2 \mathrm{mM}\left(\mathrm{CH}_{3}\right) \gamma$ - $\mathrm{TOH}$ in $\mathrm{CH}_{3} \mathrm{CN}$ with $0.5 \mathrm{M} \mathrm{Bu}_{4} \mathrm{NPF}_{6}$ at a scan rate of $0.5 \mathrm{~V} \mathrm{~s}^{-1}$ at variable temperatures at a $1 \mathrm{~mm}$ diameter Pt electrode. (-) Experimental data. (---) Digital simulations (see parameters in Tables 1 and 2).

organic solvents; hence the hemiketal forms by a hydrolysis reaction of the reactive phenoxonium cation with trace water. The hemiketal is itself not stable and further isomerizes to form the $p$-quinone (Scheme 5, TOQ). Evidence for the isomerization reaction (Scheme 5, $k_{\mathrm{f}(3)}$ ) is detectable in the voltammograms at slow scan rates, because the peak at $-0.3 \mathrm{~V}$ vs $\mathrm{Fc} / \mathrm{Fc}^{+}$(due to the hydrolysis product) initially increases in size as the scan rate is increased from 0.1 to $1 \mathrm{~V} \mathrm{~s}^{-1}$, due to the isomerization reaction being outrun. At scan rates faster than $\sim 1 \mathrm{~V} \mathrm{~s}^{-1}$, the hydrolysis reaction (Scheme $5, k_{\mathrm{f}(2)}$ ) is also outrun; hence the peak at $-0.3 \mathrm{~V}$ diminishes in size until it is undetectable at $v$ $=10 \mathrm{~V} \mathrm{~s}^{-1}$.

The rate constants for the secondary processes $\left[k_{\mathrm{f}(2)}, k_{\mathrm{b}(2)}, k_{\mathrm{f}(3)}\right.$, and $\left.k_{\mathrm{b}(3)}\right]$ that occur for $\left(\mathrm{CH}_{3}\right) \gamma-\mathrm{TOH},\left(\mathrm{CH}_{3}\right) \delta-\mathrm{TOH}$, and $\left(\mathrm{CH}_{3}\right) \mathrm{H}_{3}-\mathrm{TOH}$ (Scheme 5) were much slower than the proton transfer step $\left[k_{\mathrm{f}(1)}\right.$ and $\left.k_{\mathrm{b}(1)}\right]$; thus systematic differences could be observed in the voltammograms as the temperature was changed. Figure 6 shows $\mathrm{CVs}$ of $\left(\mathrm{CH}_{3}\right) \gamma-\mathrm{TOH}$ at several temperatures (the $\mathrm{CVs}$ of $\left(\mathrm{CH}_{3}\right) \delta$ - TOH and $\left(\mathrm{CH}_{3}\right) \mathrm{H}_{3}-\mathrm{TOH}$ were qualitatively similar). The most obvious change to the voltammograms was that the peak for the reduction of the phenoxonium cation became larger as the temperature was lowered, due to its increased lifetime (Figure 6). Concomitantly to the peak for the reduction of the phenoxonium cation becoming larger at low temperature, the peak for the reduction of the hemiketal at $-0.3 \mathrm{~V}$ vs $\mathrm{Fc} / \mathrm{Fc}^{+}[\mathrm{TOQ}(\mathrm{OH})]$ became smaller.

The entire oxidation mechanism for the phenols is thus given in Scheme 5, with the corresponding kinetic data obtained by digital simulations summarized in Tables 1 and 2. For $\left(\mathrm{CH}_{3}\right) \alpha-$ $\mathrm{TOH}$, only the first three steps occur (two one-electron transfers and one proton transfer) on the $\mathrm{CV}$ time scale, to reversibly form the phenoxonium cation $\left(\mathrm{TO}^{+}\right)$. However, for the less methylated compounds, $k_{\mathrm{f}(2)}$ and $k_{\mathrm{f}(3)}$ are sufficiently fast to be detectable by $\mathrm{CV}$ experiments and so affect the appearance of the voltammograms as the scan rate and temperature are varied. The large number of steps in the overall mechanism meant that the rate and equilibrium constants for the secondary chemical steps could only be estimated to one significant figure (Table 2).

3.3. Discussion on Electrochemical Data. Some conclusions can be drawn from the electrochemical, equilibrium, and kinetic values presented in Tables 1 and 2. The effect of the electrondonating methyl groups can be seen in the first and second electron transfer steps (Table $1, E_{\mathrm{f}(1)}^{0}$ and $E_{\mathrm{f}(2)}^{0}$ ) which shift to more positive potentials with decreasing number of methyl groups in the aromatic ring, so that the one-electron oxidation potentials increase in the order $\left(\mathrm{CH}_{3}\right) \alpha-\mathrm{TOH}<\left(\mathrm{CH}_{3}\right) \gamma-\mathrm{TOH}$ $<\left(\mathrm{CH}_{3}\right) \delta-\mathrm{TOH}<\left(\mathrm{CH}_{3}\right) \mathrm{H}_{3}-\mathrm{TOH}$.

Another observation from the digital modeling studies is that the equilibrium constant for the proton transfer $\left(K_{\text {eq (1) }}\right)$ is $<1$ mol L $\mathrm{L}^{-1}$, which accounts for the ECE portion of the mechanism being chemically reversible for all of the compounds at all measured scan rates. Furthermore, the chemical reversibility of the protonation reaction is assisted by the second-order rate constant $\left(k_{\mathrm{b}(1)}\right)$ being very fast (approaching diffusion controlled for $\left.\left(\mathrm{CH}_{3}\right) \alpha-\mathrm{TOH}\right)$. One explanation for the very fast protonation reaction would be the occurrence of a proton tunneling mechanism, ${ }^{19}$ which has been shown to take place for vitamin $\mathrm{E}$ when the phenolic starting material $(\alpha-\mathrm{TOH})$ reacts with an oxidized site on a lipid cell wall (LOO*) to form the phenoxyl radical $\left(\alpha-\mathrm{TO}^{*}\right)$ and lipid hydroperoxide $(\mathrm{LOOH}){ }^{20}$ Other organic cation radicals have also been shown to undergo proton tunneling mechanisms in $\mathrm{CH}_{3} \mathrm{CN} .{ }^{21}$ It is important that the protonation reaction is fast, because the $\mathrm{TO}^{\circ}$ radicals are known to decay by a bimolecular self-reaction with a rate constant of around $1 \times 10^{3} \mathrm{~L} \mathrm{~mol}^{-1} \mathrm{~s}^{-1}$ (for $\alpha$-TO') in acetonitrile at $293 \mathrm{~K},{ }^{6 \mathrm{a}}$ although the values vary in other solvents and with other tocopherols. ${ }^{2 b, 22}$ Thus, if the protonation reactions were slow, the $\mathrm{TO}^{\bullet}$ radicals would irreversibly react before the cations could be reduced back to starting material. The bimolecular decay reaction $\left(\right.$ Scheme $5, k_{\text {bimolec }}=1 \times 10^{3} \mathrm{~L} \mathrm{~mol}^{-1} \mathrm{~s}^{-1}$ ) was included in the overall mechanism, although its inclusion did not affect the appearance of the simulated voltammograms.

The equilibrium constants for the follow-up chemical reactions $\left(K_{\mathrm{eq}(2)}\right.$ and $\left.K_{\mathrm{eq}(3)}\right)$ for the less methylated tocopherols $\left[\left(\mathrm{CH}_{3}\right) \gamma-\mathrm{TOH}\right.$ and $\left.\left.\left(\mathrm{CH}_{3}\right) \delta-\mathrm{TOH}\right)\right]$ and tocol $\left[\left(\mathrm{CH}_{3}\right) \mathrm{H}_{3}-\mathrm{TOH}\right]$ are $>1$ (200-1000 $\mathrm{L} \mathrm{mol}^{-1}$ and 500, respectively], indicating that the forward reactions (hydrolysis and isomerization, respectively) were favored (Table 2). The rate constants for the hydrolysis processes $\left(k_{\mathrm{f}(2)}\right)$ increased in the order $\left(\mathrm{CH}_{3}\right) \alpha-\mathrm{TOH}$ $<\left(\mathrm{CH}_{3}\right) \gamma-\mathrm{TOH} \approx\left(\mathrm{CH}_{3}\right) \delta-\mathrm{TOH}<\left(\mathrm{CH}_{3}\right) \mathrm{H}_{3}-\mathrm{TOH}$, with decreasing methylation of the aromatic ring (Table 2). Therefore, it appears that one of the reasons for the long lifetime of the phenoxonium cation of $\alpha$-TOH (and $\left(\mathrm{CH}_{3}\right) \alpha-\mathrm{TOH}$ ) in $\mathrm{CH}_{3} \mathrm{CN}$ is that it is relatively stable toward the hydrolysis reaction $\left(k_{\mathrm{f}(2)}\right)$ that occurs for the less methylated tocols and tocopherols. The rate constant values for the hydrolysis and isomerization reactions $\left[k_{\mathrm{f}(2)}\right.$ and $k_{\mathrm{f}(3)}$ ] decreased as the temperature was lowered.

A key factor in the appearance of the voltammetric responses is the moisture content of the solvent. Since the hydrolysis reaction is the major route of reaction of the phenoxonium cations in $\mathrm{CH}_{3} \mathrm{CN}$ at millimolar concentrations, small amounts of water will affect the CVs and, therefore, the kinetic values 
TABLE 3: Results from Theoretical Calculations at the B3LYP/6-31G* Level for the Phenoxonium Cations of the Tocopherols

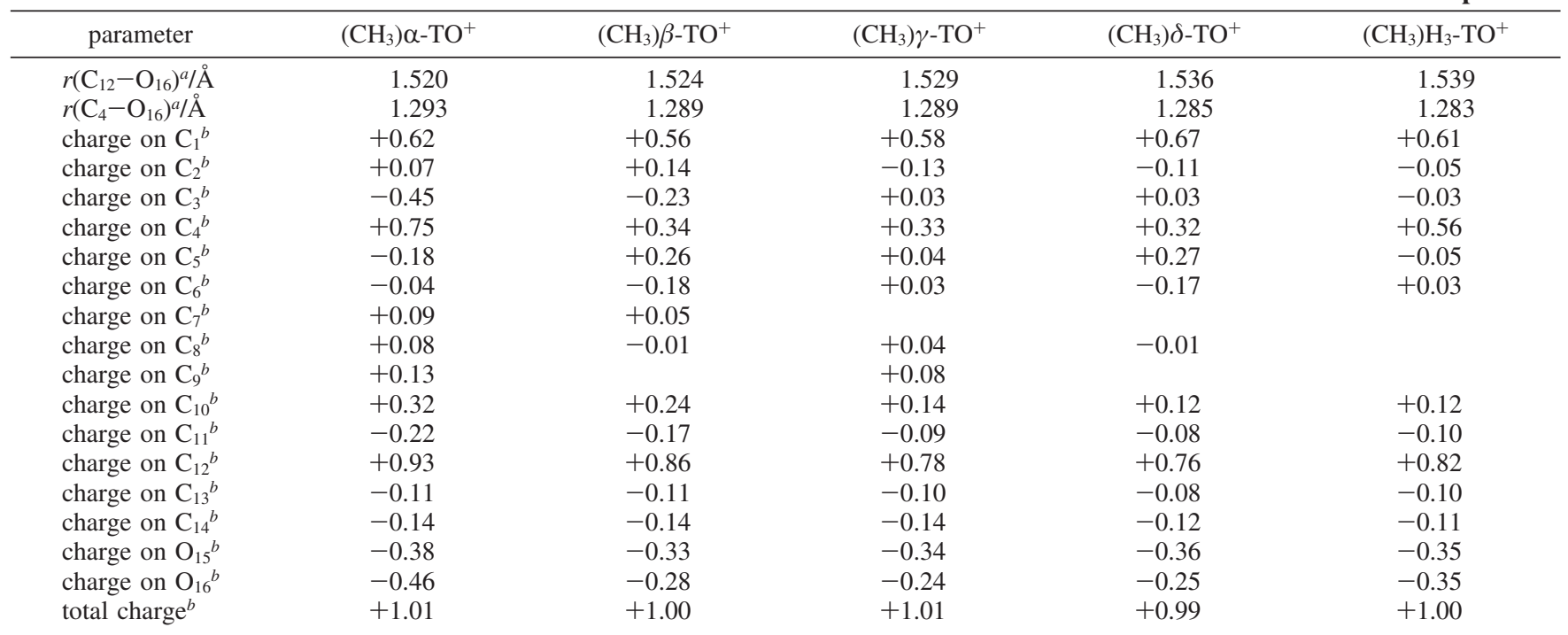

${ }^{a}$ Bond length. ${ }^{b}$ Electrostatic potential derived charges. Atomic numbering system is given in Scheme 6.

for the reactions in Scheme 5. Nevertheless, since the CV experiments were all performed under identical conditions, the relative lifetimes of the phenoxonium cations given in Tables 1 and 2 are valid. It is possible that the increased equilibrium solubility of water in DMSO and DMF could account for decreased lifetimes of the phenoxonium cations in those media. Direct reactions of the cationic compounds with the solvents are also possible, especially in the case of DMSO. DMSO undergoes a self-ionization reaction, and its conjugate base $\left(\mathrm{CH}_{3} \mathrm{SOCH}_{2}{ }^{-}\right)$is a good nucleophile which may attack electrophilic centers. The $\alpha$-tocopherol quinone product (TOQ) was not voltammetrically detected after oxidation of $\left(\mathrm{CH}_{3}\right) \alpha-\mathrm{TOH}$ in DMSO or DMF, suggesting that the long-time-scale reaction(s) in DMSO and DMF were more complicated than hydrolysis of the phenoxonium cation. At high concentrations or in very low dielectric constant solvents such as benzene or chlorobenzene, dimeric compounds are often identified as oxidation products of tocopherols. ${ }^{2 b, 18 d}$

The addition of strong organic acids, such as $\mathrm{CF}_{3} \mathrm{SO}_{3} \mathrm{H}$ or $\mathrm{CF}_{3} \mathrm{COOH}$, has a pronounced effect on the appearance of the voltammograms. ${ }^{4,6 a, b, d}$ As well as increasing the proton concentration, the acid also decreases the moisture content of the solvent and thereby changes the solvent composition $\left(\mathrm{CF}_{3} \mathrm{SO}_{3} \mathrm{H}\right.$ reacts with $\mathrm{H}_{2} \mathrm{O}$ to form the monohydrate, $\left.\mathrm{CF}_{3} \mathrm{SO}_{3} \mathrm{H} \cdot \mathrm{H}_{2} \mathrm{O}^{23}\right)$. It has been shown that reactive cation radicals (such as $\mathrm{C}_{60}{ }^{\circ+}$ ) ${ }^{24}$ are stabilized in organic solvents containing organic-soluble acids, by the acids reacting preferentially with trace nucleophiles (such as water), and the same situation can occur with $\mathrm{TOH}^{\bullet+}$ and $\mathrm{TO}^{+} .6 \mathrm{~d}$

\section{Theoretical Calculations}

One interesting question relates to why some phenoxonium cations have longer lifetimes in solution than others; in particular, large differences in lifetime exist between $\alpha-\mathrm{TO}^{+}$ and the phenoxonium cations of the other tocols and tocopherols, despite relatively small differences in their structures. Therefore, the phenoxonium cations were investigated by molecular orbital calculations to determine their molecular structures and the positive charge distributions. The calculations were performed on the gas phase molecules, and do not take into account the more complex interactions that occur between the cations and the solvent molecules. Nevertheless, the theoretical results do
SCHEME 6: Atomic Numbering System for the Theoretical Values Given in Table $\mathbf{3}^{a}$<smiles>CC1=C(C)C2OC(C)(C)C(C)=C(C)C2=C(C)C1=[18O]</smiles>

${ }^{a}$ Hydrogen atoms are omitted for clarity.

indicate some interesting differences between the different tocopherol phenoxonium ions.

It was known from the crystal structure of $\left(\mathrm{CH}_{3}\right) \alpha-\mathrm{TO}^{+6 \mathrm{~d}}$ that the bond distance between the oxygen atom and the quaternary carbon atom $\left(\mathrm{C}_{12}-\mathrm{O}_{16}\right.$ in Table 3$)$ was relatively long for a carbon-oxygen bond (1.52 $\AA$ compared to $1.44 \AA$ for a normal $\mathrm{C}-\mathrm{O}$ bond). It was rationalized that the chromanol ring structure helped to maintain the $\mathrm{C}_{12}-\mathrm{O}_{16}$ bond intact despite it being long and, therefore, weak. The results in Table 3 indicate that the length of the $\mathrm{C}_{12}-\mathrm{O}_{16}$ bond in the phenoxonium cations do increase as the degree of methyl substitution decreases. The calculations also indicate that, as the $\mathrm{C}_{12}-\mathrm{O}_{16}$ bond length increases between the different phenoxonium cations, the $\mathrm{C}_{4}-\mathrm{O}_{16}$ bond length correspondingly decreases.

Table 3 contains the calculated electrostatic potential derived charges, where the charges on the hydrogen atoms are absorbed into their parent carbons, which show a number of interesting differences between $\left(\mathrm{CH}_{3}\right) \alpha-\mathrm{TO}^{+}$and the other phenoxonium cations. If the total positive charge in the aromatic ring is summed, the charge increases in the order $\left(\mathrm{CH}_{3}\right) \alpha-\mathrm{TO}^{+}(+0.77)$ $<\left(\mathrm{CH}_{3}\right) \beta-\mathrm{TO}^{+}(+0.89) \approx\left(\mathrm{CH}_{3}\right) \gamma-\mathrm{TO}^{+}(0.88)<\left(\mathrm{CH}_{3}\right) \delta-\mathrm{TO}^{+}$ $(+1.01)<\left(\mathrm{CH}_{3}\right) \mathrm{H}_{3}-\mathrm{TO}^{+}(+1.07)$. It could be concluded that the increasing positive charge in the aromatic ring favors an increased rate of reaction with nucleophiles and, therefore, results in a decrease in lifetime in solution. However, the calculations also indicate that most of the positive charge in the aromatic ring is located on $\mathrm{C}_{1}$ and $\mathrm{C}_{4}$, and for $\left(\mathrm{CH}_{3}\right) \alpha$ - 
$\mathrm{TO}^{+}$, the positive charge on $\mathrm{C}_{4}$ is extremely high compared to the other phenoxonium cations. Considering that nucleophilic attack on $\mathrm{C}_{4}$ is a major reaction route for the phenoxonium cations, the high positive charge on $\mathrm{C}_{4}$ for $\left(\mathrm{CH}_{3}\right) \alpha-\mathrm{TO}^{+}$seems counterintuitive to its long lifetime in solution. This argument does not take into account the steric hindrance that the $\mathrm{C}_{8}$ methyl group would be expected to have in preventing nucleophilic attack at $\mathrm{C}_{4}$ [which is not present in $\left(\mathrm{CH}_{3}\right) \mathrm{H}_{3}-\mathrm{TO}^{+}$].

A further interesting result from the electrostatic potential derived charges is that, for $\left(\mathrm{CH}_{3}\right) \alpha-\mathrm{TO}^{+}$, the ether oxygen (Scheme 6, $\mathrm{O}_{16}$ ) carries a high negative charge compared to the other phenoxonium cations $(-0.46$ compared to between -0.24 and -0.35 ) (Table 3 ). The high negative charge on $\mathrm{O}_{16}$ could provide a mechanism for electrostatic repulsion for incoming nucleophiles, thereby decreasing the solution phase reaction rate. The calculations predict that the negative charge on $\mathrm{O}_{16}$ in $\left(\mathrm{CH}_{3}\right) \alpha-\mathrm{TO}^{+}$is even higher than on the carbonyl oxygen $\left(\mathrm{O}_{15}\right)$, while for the other compounds the negative charge on $\mathrm{O}_{16}<\mathrm{O}_{15}$ (except for $\left(\mathrm{CH}_{3}\right) \mathrm{H}_{3}-\mathrm{TO}^{+}$, where the charges on the oxygen atoms are equal). Therefore, for $\left(\mathrm{CH}_{3}\right) \alpha-\mathrm{TO}^{+}$, the anisotropic effect of the carbonyl group $\left(\mathrm{C}_{1}-\mathrm{O}_{15}\right)$ hinders nucleophilic attack from the direction of the carbonyl group, the steric effect of the $\mathrm{C}_{8}$ methyl group prevents nucleophilic attack across the open-side double bond, and the electronegative oxygen $\left(\mathrm{O}_{16}\right)$ hinders nucleophilic addition from the direction of the chromanol ring.

\section{Conclusions}

The electrochemical oxidation of tocol and the tocopherols in $\mathrm{CH}_{3} \mathrm{CN}$ and $\mathrm{CH}_{2} \mathrm{Cl}_{2}$ initially proceeds via an $\mathrm{ECE}$ mechanism to form phenoxonium cations. Digital simulation of variable scan rate cyclic voltammetric data allowed an estimation of the rate constants of the electrochemical and chemical steps. The rate constants for the protonation reaction (C-step) are fast, resulting in equilibrium constants that favor the oxidation processes being chemically reversible. The phenoxonium cations of the less methylated compounds (tocol and $\gamma$ - and $\delta$-tocopherol) are able to undergo a hydrolysis reaction on the voltammetric time scale to form hemiketals which isomerize into $p$-quinones. The rate constants for the hydrolysis reaction $\left(k_{\mathrm{f}(2)}\right)$ increase with decreasing methylation of the aromatic ring $\left[\left(\mathrm{CH}_{3}\right) \alpha-\mathrm{TO}^{+}<\left(\mathrm{CH}_{3}\right) \gamma-\mathrm{TO}^{+} \approx\left(\mathrm{CH}_{3}\right) \delta-\mathrm{TO}^{+}<\left(\mathrm{CH}_{3}\right) \mathrm{H}_{3}-\mathrm{TO}^{+}\right]$. In contrast to $\mathrm{CH}_{3} \mathrm{CN}$ and $\mathrm{CH}_{2} \mathrm{Cl}_{2}$, the oxidation of $\left(\mathrm{CH}_{3}\right) \alpha-$ $\mathrm{TOH}$ in DMF and DMSO showed no evidence of chemical reversibility at scan rates up to $500 \mathrm{~V} \mathrm{~s}^{-1}$, indicating that the lifetime of the phenoxonium cation was considerably less (than in $\mathrm{CH}_{3} \mathrm{CN}$ and $\mathrm{CH}_{2} \mathrm{Cl}_{2}$ ).

The results from theoretical calculations indicated a number of systematic differences between the different tocopherols in terms of atomic bond lengths and charges. The reason for the increased lifetime in solution for $\left(\mathrm{CH}_{3}\right) \alpha-\mathrm{TO}^{+}$, compared to the other phenoxonium cations, is likely to be because of a complicated mixture of the charge distribution (resulting in electrostatic repulsions) and steric hindrance, affecting its interactions with nucleophiles.

Acknowledgment. This work was supported by a Nanyang Technological University research grant (SUG42/06).

Supporting Information Available: Results from theoretical molecular orbital calculations. This material is available free of charge via the Internet at http://pubs.acs.org.

\section{References and Notes}

(1) Traber, M. G.; Atkinson, J. Free Radical Biol. Med. 2007, 43, 4-
(2) (a) Burton, G. W.; Ingold, K. U. Acc. Chem. Res. 1986, 19, 194 201. (b) Bowry, V. W.; Ingold, K. U. J. Org. Chem. 1995, 60, 5456-5467. (c) Bowry, V. W.; Ingold, K. U. Acc. Chem. Res. 1999, 32, 27-34.

(3) (a) Azzi, A.; Stocker, A. Prog. Lipid Res. 2000, 39, 231-255. (b) Ricciarelli, R.; Zingg, J.-M.; Azzi, A. Biol. Chem. 2002, 383, 457-465. (c) Azzi, A.; Ricciarelli, R.; Zingg, J.-M. FEBS Lett. 2002, 519, 8-10. (d) Melton, L. New Sci. 2006, 191, 40-43. (e) Azzi, A. Free Radical Biol. Med. 2007, 43, 16-21. (f) Azzi, A. Biochem. Biophys. Res. Commun. 2007, 362, 230-232.

(4) (a) Parker, V. D. J. Am. Chem. Soc. 1969, 91, 5380-5381. (b) Svanholm, U.; Bechgaard, K.; Parker, V. D. J. Am. Chem. Soc. 1974, 96, 2409-2413.

(5) Nanni, E. J., Jr.; Stallings, M. D.; Sawyer, D. T. J. Am. Chem. Soc. 1980, 102, 4481-4485.

(6) (a) Webster, R. D. Electrochem. Commun. 1999, 1, 581-584. (b) Williams, L. L.; Webster, R. D. J. Am. Chem. Soc. 2004, 126, 1244112450. (c) Lee, S. B.; Lin, C. Y.; Gill, P. M. W.; Webster, R. D. J. Org. Chem. 2005, 70, 10466-10473. (d) Wilson, G. J.; Lin, C. Y.; Webster, R. D. J. Phys. Chem. B 2006, 110, 11540-11548. (e) Lee, S. B.; Willis, A. C.; Webster, R. D. J. Am. Chem. Soc. 2006, 128, 9332-9333. (f) Webster, R. D. Acc. Chem. Res. 2007, 40, 251-257. (g) Peng, H. M.; Webster, R. D. J. Org. Chem. 2008, 73, 2169-2175.

(7) (a) Speiser, B.; Rieker, A. J. Chem. Res.,Synop. 1977, 314, 315. (b) Speiser, B.; Rieker, A. J. Electroanal. Chem. 1979, 102, 373-395. (c) Speiser, B.; Rieker, A. J. Electroanal. Chem. 1980, 110, 231-246. (d) Hammerich, O. ; Svensmark, B. In Organic Electrochemistry, 3rd ed.; Lund, H., Baizer, M. M., Eds.; Marcel Dekker: New York, 1991; Chapter 16. (e) Rieker, A.; Beisswenger, R.; Regier, K. Tetrahedron 1991, 47, 645-654. (f) Eickhoff, H.; Jung, G.; Rieker, A. Tetrahedron 2001, 57, 353-364.

(8) (a) Costentin, C.; Robert, M.; Savéant, J.-M. Chem. Phys. 2006, 324, 40-56. (b) Costentin, C.; Robert, M.; Savéant, J.-M. J. Am. Chem. Soc. 2006, 128, 4552-4553. (c) Rhile, I. J.; Markle, T. F.; Nagao, H.; DiPasquale, A. G.; Lam, O. P.; Lockwood, M. A.; Rotter, K.; Mayer, J. M. J. Am. Chem. Soc. 2006, 128, 6075-6088.

(9) (a) Wang, Q.; She, X.; Ren, X.; Ma, J.; Pan, X. Tetrahedron: Asymmetry 2004, 15, 29-34. (b) Ismail, F. M. D.; Hilton, M. J.; Štefinović, M. Tetrahedron Lett. 1992, 33, 3795-3796, and references cited within.

(10) (a) Smith, L. I.; Ungnade, H. E.; Hoehn, H. H.; Wawzonek, S. J. Org. Chem. 1939, 4, 311-317. (b) Smith, L. I.; Tess, R. W. H. J. Am. Chem. Soc. 1944, 66, 1523-1525. (c) Lien, E. J.; Ren, S. J.; Bui, H. Y. H.; Wang, R. B. Free Radical Biol. Med. 1999, 26, 285-294. (d) Wright, J. S.; Johnson, E. R.; DiLabio, G. A. J. Am. Chem. Soc. 2001, 123, 1173-1183.

(11) Fry, A. J. ; Britton, W. E. In Laboratory Techniques in Electroanalytical Chemistry; Kissinger, P. T., Heineman, W. R., Eds.; Marcel Dekker: New York, 1984; Chapter 13.

(12) (a) Rudolph, M. J. Electroanal. Chem. 2003, 543, 23-29. (b) Rudolph, M. J. Electroanal. Chem. 2004, 571, 289-307. (c) Rudolph, M. J. Electroanal. Chem. 2003, 558, 171-176. (d) Rudolph, M. J. Comput. Chem. 2005, 26, 619-632. (e) Rudolph, M. J. Comput. Chem. 2005, 26, 633-641. (f) Rudolph, M. J. Comput. Chem. 2005, 26, 1193-1204.

(13) Shao, Y.; Fusti Molnar, L.; Jung, Y.; Kussmann, J.; Ochsenfeld, C.; Brown, S. T.; Gilbert, A. T. B.; Slipchenko, L. V.; Levchenko, S. V.; O'Neill, D. P.; DiStasio, R. A., Jr.; Lochan, R. C.; Wang, T.; Beran, G. J. O.; Besley, N. A.; Herbert, J. M.; Lin, C. Y.; Van Voorhis, T.; Chien, S. H.; Sodt, A.; Steele, R. P.; Rassolov, V. A.; Maslen, P. E.; Korambath, P. P.; Adamson, R. D.; Austin, B.; Baker, J.; Byrd, E. F. C.; Dachsel, H.; Doerksen, R. J.; Dreuw, A.; Dunietz, B. D.; Dutoi, A. D.; Furlani, T. R.; Gwaltney, S. R.; Heyden, A.; Hirata, S.; Hsu, C.-P.; Kedziora, G.; Khalliulin, R. Z.; Klunzinger, P.; Lee, A. M.; Lee, M. S.; Liang, W.; Lotan, I.; Nair, N.; Peters, B.; Proynov, E. I.; Pieniazek, P. A.; Rhee, Y. M.; Ritchie, J.; Rosta, E.; Sherrill, C. D.; Simmonett, A. C.; Subotnik, J. E.; Woodcock, H. L., III; Zhang, W.; Bell, A. T.; Chakraborty, A. K.; Chipman, D. M.; Keil, F. J.; Warshel, A.; Hehre, W. J.; Schaefer, H. F., III; Kong, J.; Krylov, A. I.; Gill, P. M. W.; Head-Gordon, M. Phys. Chem. Chem. Phys. 2006, 8, 3172-3191.

(14) Spartan '04 for Macintosh, Wavefunction Inc., Irvine CA.

(15) (a) Amatore, C.; Savéant, J. M. J. Electroanal. Chem. 1980, 107, 353-364. (b) Compton, R. G.; Pilkington, M. B. G.; Stearn, G. M. J. Chem. Soc., Faraday Trans. 1 1988, 84, 2155-2171. (c) Neudeck, A.; Dittrich, J. J. Electroanal. Chem. 1989, 264, 91-119. (d) Compton, R. G.; Coles, B. A.; Pilkington, M. B. G.; Bethell, D. J. Chem. Soc., Faraday Trans. 1990, 86, 663-670. (e) Compton, R. G.; Dryfe, R. A. W. J. Electroanal. Chem. 1994, 375 (1-2), 247-255. (f) Leslie, W. M.; Alden, J. A.; Compton, R. G.; Silk, T. J. Phys. Chem. 1996, 100, 14130-14136. (g) Leslie, W. M.; Compton, R. G.; Silk, T. Electrochim. Acta 1997, 42, 3575-3584. (h) Alden, J. A.; Compton, R. G. J. Phys. Chem. B 1997, 101, 9606-9616.

(16) Bond, A. M.; Henderson, T. L. E.; Mann, D. R.; Mann, T. F.; Thormann, W.; Zoski, C. G. Anal. Chem. 1988, 60, 1878-1882.

(17) Organic Electrochemistry, 4th ed.; Lund, H., Hammerich, O., Eds.; Marcel Dekker: New York, 2001; Chapter 5.

(18) (a) Dürckheimer, W.; Cohen, L. A. J. Am. Chem. Soc. 1964, 86, 4388-4393. (b) Marcus, M. F.; Hawley, M. D. J. Org. Chem. 1970, 35, 2185-2190. (c) Patel, A.; Netscher, T.; Gille, L.; Mereiter, K.; Rosenau, T. 
Tetrahedron 2007, 63, 5312-5318. (d) Rosenau, T.; Klosner, E.; Gille, L.; Mazzini, F.; Netscher, T. J. Org. Chem. 2007, 72, 3268-3281.

(19) Bell, R. P. The Tunnel Effect in Chemistry; Chapman and Hall: London, 1980.

(20) (a) Nagaoka, S.; Kuranaka, A.; Tsuboi, H.; Nagashima, U.; Mukai, K. J. Phys. Chem. 1992, 96, 2754-2761. (b) Nagaoka, S.; Sawada, K.; Fukumoto, Y.; Nagashima, U.; Katsumata, S.; Mukai, K. J. Phys. Chem. 1992, 96, 6663-6668. (c) Nagaoka, S.; Mukai, K.; Itoh, T.; Katsumata, S. J. Phys. Chem. 1992, 96, 8184-8187. (d) Nagaoka, S.; Inoue, M.; Nishioka, C.; Nishioku, Y.; Tsunoda, S.; Ohguchi, C.; Ohara, K.; Mukai, K.; Nagashima, U. J. Phys. Chem. B 2000, 104, 856-862.

(21) Lu, Y.; Zhao, Y.; Parker, V. D. J. Am. Chem. Soc. 2001, 123, 59005907.
(22) (a) Doba, T.; Burton, G. W.; Ingold, K. U.; Matsuo, M. J. Chem. Soc., Chem. Commun. 1984, 461, 462. (b) Rousseau-Richard, C.; Richard, C.; Martin, R. FEBS Lett. 1988, 233, 307-310. (c) Watanabe, A.; Noguchi, N.; Fujisawa, A.; Kodama, T.; Tamura, K.; Cynshi, O.; Niki, E. J. Am. Chem. Soc. 2000, 122, 5438-5442.

(23) Cotton, F. A.; Wilkinson, G.; Murillo, C. A.; Bochman, M. In Advanced Inorganic Chemistry, 6th ed.; Wiley-Interscience: New York, $1999 ; \mathrm{p} 74$.

(24) Webster, R. D.; Heath, G. A. Phys. Chem. Chem. Phys. 2001, 3, 2588-2594.

JP710995N 